Review Article

\title{
A Cutting-Edge Survey of Tribological Behavior Evaluation Using Artificial and Computational Intelligence Models
}

\author{
Senthil Kumaran Selvaraj $\mathbb{D},{ }^{1}$ Aditya Raj $\mathbb{D}^{2},{ }^{2}$ Mohit Dharnidharka $\mathbb{D}^{1},{ }^{1}$ Utkarsh Chadha $\mathbb{D}^{1},{ }^{1}$ \\ Isha Sachdeva $\mathbb{D}^{2},{ }^{2}$ Chinmay Kapruan $\mathbb{D},{ }^{1}$ and Velmurugan Paramasivam $\mathbb{D}^{3}$ \\ ${ }^{1}$ Department of Manufacturing Engineering, School of Mechanical Engineering (SMEC), Vellore Institute of Technology (VIT), \\ Vellore, Tamilnadu 632014, India \\ ${ }^{2}$ School of Information Technology and Engineering (SITE), Vellore Institute of Technology (VIT), Vellore, \\ Tamilnadu 632014, India \\ ${ }^{3}$ School of Mechanical and Automotive Engineering, College of Engineering and Technology, Dilla University, P.O. Box 419, \\ Dilla, Ethiopia
}

Correspondence should be addressed to Senthil Kumaran Selvaraj; senthilkumaran.s@vit.ac.in and Velmurugan Paramasivam; drvelmuruganp@du.edu.et

Received 28 October 2021; Revised 14 December 2021; Accepted 16 December 2021; Published 29 December 2021

Academic Editor: Ali Khorram

Copyright (C) 2021 Senthil Kumaran Selvaraj et al. This is an open access article distributed under the Creative Commons Attribution License, which permits unrestricted use, distribution, and reproduction in any medium, provided the original work is properly cited.

\begin{abstract}
Any metal surface's usefulness is essential in various applications such as machining and welding and aerospace and aerodynamic applications. There is a great deal of wear in metals, used widely in machines and appliances. The gradual loss of the upper metal layers in all metal parts is inevitable over the machine or component's lifetime. Artificial intelligence implementations and computational models are being studied to evaluate different metals' tribological behavior, as technological progress has been made in this field. Different neural networks were used for different metals. They are classified in this paper, together with a description of their benefits and inconveniences and an overview and use of the different types of wear. Artificial intelligence is a relatively new term that uses mechanical engineering. There is still no scientific progress to examine various metal wear cases and compare AI and computational models' accuracy in wear behavior.
\end{abstract}

\section{Introduction}

Given the potential and technological developments we have experienced in an industrial revolution, we have a long path to cover as engineers. The wear behavior varies from metal to metal, mainly depending on its properties or the method used, and AI has helped companies better understand metals' wearing behavior and deploy them in processes or machinery because the speed with precision is more critical in the industry, helping companies increase their response speed. Artificial intelligence is a computer science field dealing with the simulation of computer systems to imitate human intelligence. $\mathrm{AI}$ is a large field in computers and other areas such as economics, theory of control, probability, optimization, and bilingualism. AI is such a phenomenon that it can model and find patterns in complex inputs and outputs on the given data. It has been made an essential element of our lives without even realizing weather prediction, mechanical wear and tear, the probability of different diseases, and many more, as recommended by Netflix and YouTube. An AI process consists of data acquisition and correction to enhance its earlier forecasts over time. Mechanical engineering, as technology helps mechanical design or engineering works, is AI's biggest consumer. All sections of mechanical engineering benefiting highly from AI are robotics, automation, and sensor technology.

Wear means that the substance is consistently removed from or deformed from a solid surface while moving about another substance or fluid. Wear is a natural phenomenon when two bodies are rubbed or slipped. Mechanical and 
chemical behavior and combinations of these factors, such as corrosion, erosion, and abrasion, cause wear on the solid surface of the material. Tribology is the wear science involving friction, lubrication, and wear applications and concepts. Wear is an essential characteristic of products that must be carefully examined before producing a product. Other processes such as fatigue, material failure, and loss of functionality cause surface degradation. In the manufacturing industry, wear is a constant inconvenience, and it is expensive because it is causing loss of part and wear deterioration. The wear of the active surfaces, near-surface compositions, and fragmentation leads to wear debris caused by the plastic deformation of metals. The wear waste produced varies between nanometers and thousands. Wear can be correlated with the help of the wear rate. The material mass or volume removed by the sliding distance of each unit is the ratio. The wear volume per unit is usually expressed as a dimensionless entity called the wear coefficient on the unit's sliding distance $(\mathrm{K})$. The wear mechanism is generally considered a negative feature and is unwanted in most practical contexts, but it has many applications. Wear, for example, is affected by processes such as filing, lapping, sanding, and polishing used to create finished surfaces.

They also collected datasets, if provided, software used, benefits, and drawbacks, and all studies referred to for that survey were fully applicable to explain the subject matter of the case studies cited beforehand and cover artificial intelligence and calculation models as shown in Figure 1.

\section{Types of Wear}

We must first understand the various types of wear before applying artificial intelligence principles to evaluate wear behavior. Wear can occur due to a single mechanism or a complex combination of mechanisms. To solve a wear problem, we must first understand the various wear mechanisms at work. Abrasion or surface deterioration occurs when the force acting on the surface is caused by load stress or friction. When chemical reactions alter a material body's outer layer, the wear mechanisms responsible are adhesion and tribo-oxidation. The sections that follow describe the various types of clothing.

The most common wear process encountered in the industry is abrasive wear. According to reports, abrasion is to blame for $50 \%$ of all wear issues. Abrasive wear is the substance loss caused by hard particles being forced against and moved along a solid surface [1]. The wear mechanism that causes abrasive wear is referred to as abrasion (scraping off). Abrasion occurs when a solid body with a rough surface collides with a coupling part with a soft surface. Abrasive wear is classified into two types based on the type of contact and the contact environment.

(a) Three-body abrasion: A third dimension is included in sliding two surfaces (as shown in Figure 2), hence blaming the third body for material removal from both surfaces (particles are usually assumed the third body). (b) Two-body abrasion: This occurs when the hard material on one surface absorbs material from the opposite surface. Two-body abrasion is always possible because the asperities that cause removal on a hard surface can never be removed entirely, even with the most advanced polishing. As a result, wear debris forms between the two sliding surfaces. Long-term two-body abrasive wear causes three-body abrasion, which causes more wear than two-body abrasion.

Three mechanisms commonly cause abrasive wear:

(1) Ploughing: The displacement of particles away from the wear particles causes the formation of grooves. Ridges form on the edges of the grooves and are removed by abrasive materials moving through them.

(2) Cutting is the removal of material from a solid surface in the form of primary debris or microchips. This method is similar to traditional machining.

(3) Fragmentation occurs when the indenting material is removed from the surface, resulting in a localized fracture.

Adhesive wear: This occurs due to the interaction of asperities between two surfaces [2]. Formalized paraphrase adhesion is the wear mechanism that causes adhesive wear (stickiness). It occurs when the compositions of the two metals are incredibly similar. A bond can form because of this compatibility, allowing parts to seize or become cold-welded together (as seen in Figure 3). Because of these bonded sections' swaying and sliding motion, abrasion occurs on the bordering surfaces. Adhesive wear is classified into two types:

(a) Classifying wear due to relative motion/direct contact between two surfaces along with plastic deformation, leading to transfer of metal debris onto the other metal's surface during wear.

(b) Cohesive-adhesive forces hold two faces together even when a significant distance separates them. The actual transition could occur.

Surface fatigue: This occurs when the surface of a material is stressed. As a result of this phenomenon, which thermal or mechanical forces can cause, surfaces crack. The fatigue wear caused due to particle detachment is mainly because of cyclic increase of metal surface microcracks (as shown in Figure 4). Each period increases the crack by a small amount until a surface microcrack develops. As a result, large surface cracks develop over time, posing a direct threat to the components.

Corrosive wear/oxidation wear: This material deterioration combines corrosion and wear. It is defined as a wear phase in which materials slide against each other in a corrosive environment. It is a type of material degradation that combines corrosion and wear. It is defined as a corrosive wear process in which materials slide against each other. When there is no sliding, corrosion on the surfaces forms a micrometer-thick film layer, reducing or even preventing further corrosion. This film is chipped away during the sliding application, exposing the metal surface to further corrosion (as shown in Figure 5). This process of wear occurs in the presence of harmful or 


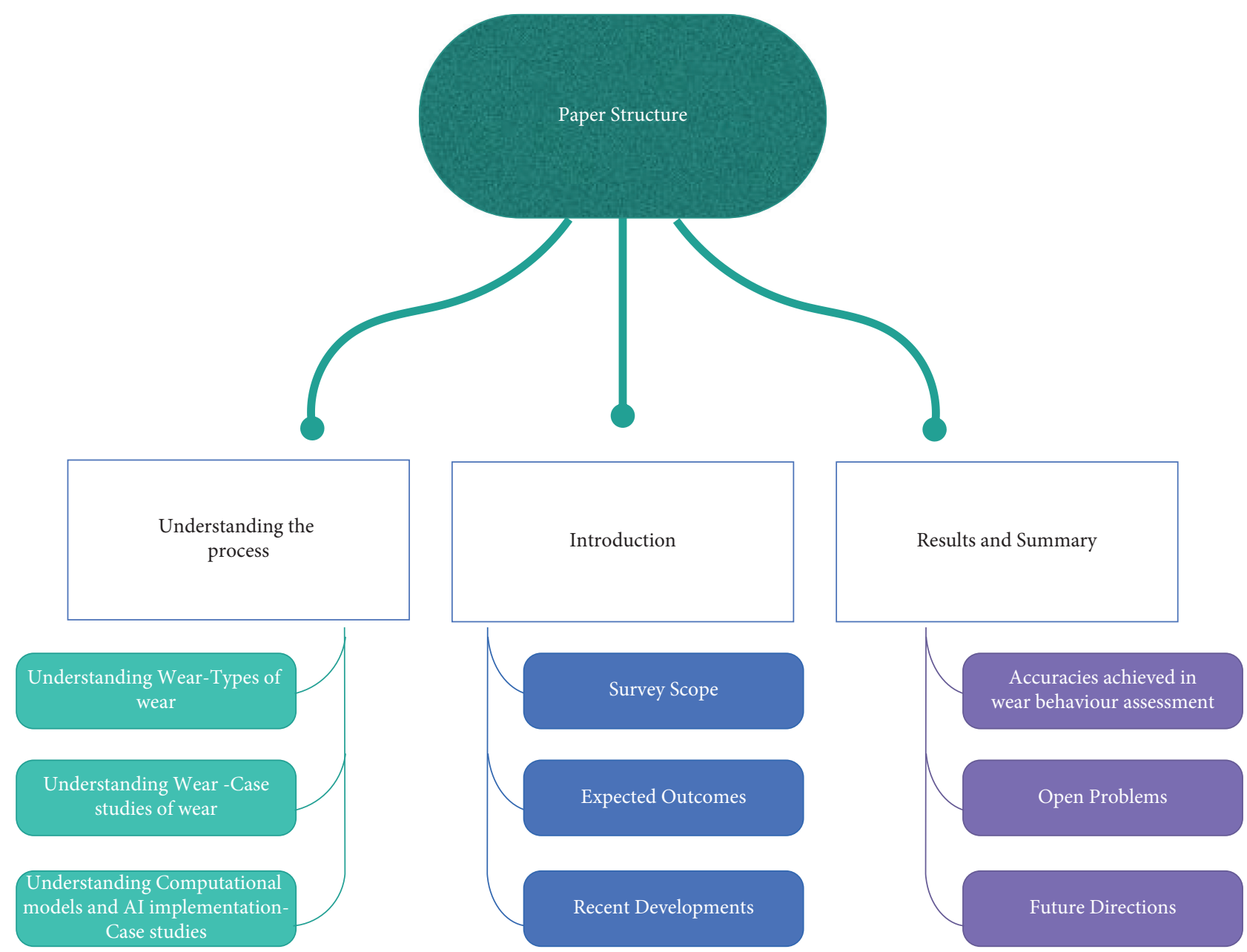

FIGURE 1: Structure of the survey paper.

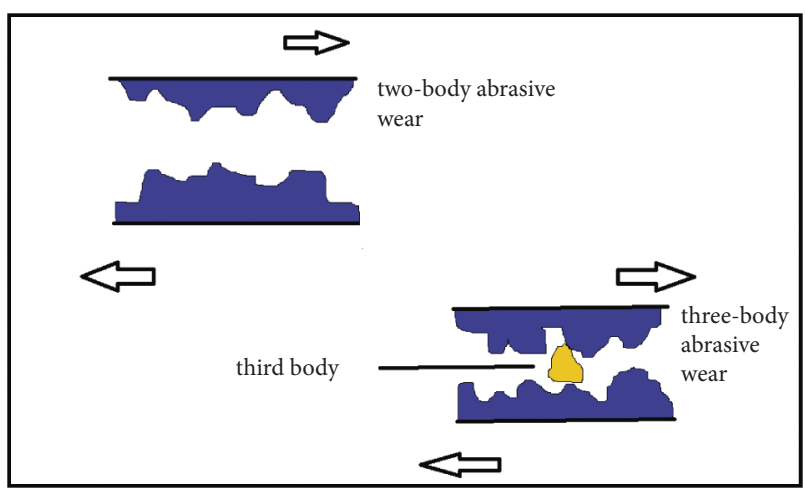

FIgURE 2: Two-body and three-body abrasive wear.

oxidizing metals. Oxidation, also known as rust, is a severe form of corrosive wear. Oxides create a decrease in the equilibrium of friction between surfaces or are often a more significant challenge to work with than the materials involved and can be used as excellent abrasives.

Cavitation wear: A liquid medium causes cavitation wear on metal surfaces. It happens when cavities in a liquid flowing near the material are nucleated, developed, and violently collapsed repeatedly. Because of the rapid changes

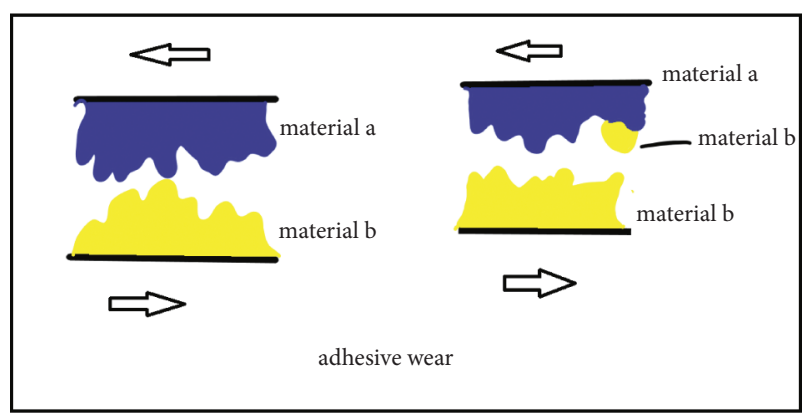

Figure 3: Adhesive wear.

in liquid pressure, small vapor-filled craters with low vapor pressure form. Cyclic stress occurs when these craters or voids collapse near a metal surface. It causes surface fatigue, which contributes to the wear of the base material over time.

\section{Wear Tests}

The wear rate is defined as the volume loss per unit sliding distance. It is a dimensionless quantity $(\mathrm{K})$ that can assess wear damage. The wear rate is defined as the body's height adjustment ratio to the relative sliding distance duration. 


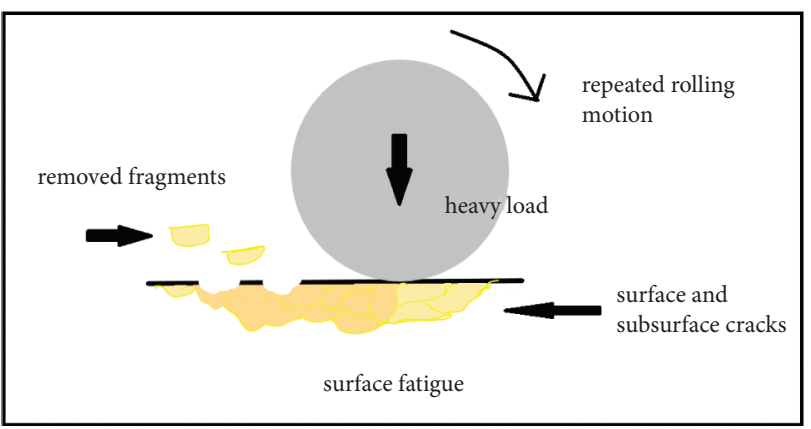

FIgURE 4: Surface fatigue.

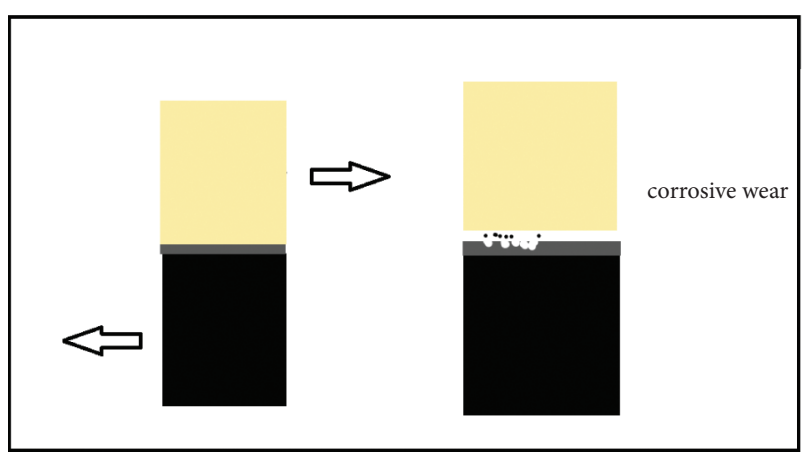

FIGURE 5: Corrosive wear.

Under normal conditions, wear progresses through three stages, the first of which is the primary stage, during which the surfaces involved adjust to one another, and the wear rate can be high or low. The second level, also known as the midage process, follows the first and is distinguished by a consistent wear rate. This process consumes the majority of the component's operating life. Finally, the component reaches the tertiary level, also known as the "old-age phase." The surfaces involved experience rapid wear, resulting in the component's premature failure [3-11].

Wear tests are classified as follows:

(1) Pin-on-Disc Wear Test. This is one of the most common ways to test wear rates and wear resistance. It is popular due to its ability to simulate various wear modes including omnidirectional, bidirectional, unidirectional, and quasi-rotational wear. Many different materials can be tested for wear. A test of wear resistance between PTFE (polytetrafluoroethylene) and its composites [12] was done using a pin-on-disc wear test, and it was observed that as the load increased, the coefficient of friction decreased. Pure PTFE experienced maximum wear followed by PTFE with 17\% GFR, PTFE with 25\% bronze, and PTFE with $35 \%$ carbon which experienced minimum wear.

(2) Block-on-Ring Wear Test. This is widely used to evaluate the sliding wear behavior of materials in various simulated conditions. It also helps in ranking material couples for specific tribological applications. A test of woven glass fibers is conducted on a block-on-ring wear testing machine [13], and it was found that aramid fiber-reinforced composites are less prone to wear than simple glass fabrics. Also, weaved 300 glass fabrics displayed better wear resistance than woven 500 glass fabrics.

(3) Abrasion Wear Test. This is used to test the abrasive resistance of materials such as metals, composites, ceramics, thick thermal spray, and weld overlay coatings.

(4) Cavitation Erosion Vibratory Test. The surface of the test sample is immersed in liquid, and the cavitation process is induced by vibrational erosion. Ultrasonic waves consisting of alternate expansions and compressions are transmitted into the liquid, which causes erosion (material loss) of the surface of the sample. This method is used to determine the relative wear resistance of test samples to cavitation erosion. In a test between HN steel and AISI 304 steel [14], the samples' cavitation wear increased with the decrease in the $\mathrm{pH}$ value of the water. Also, AISI 304 steel was more resistant to wear than HN steel.

(5) Ball-on-Flat Wear Test. This allows observing the wear tracks' dynamic load, friction force, and depth. Three different teeth from three different young males were tested using this apparatus [15], and it was observed that, for all the three teeth, three different wear scars were observed. The enamel layer displayed better wear resistance and had a lower friction coefficient than the dentin region.

\section{Wear Testing Case Studies}

Tables 1 to 5 discuss various case studies that involve various wear tests, briefly discussing the test and the implementations or additions in the metal workpiece chosen along with the observed outcomes.

\section{Computational and Artificial Intelligence Models to Detect Wear Behavior}

Artificial neural networks are a subset of AI widely used in mechanical engineering. ANNs are modelled after the biological neural system like an animal brain and are made up of neurons linked to each other that perform complex computations in the same way that the brain does. Dr. Robert Hecht-Nielson defined ANNs as " $\boldsymbol{a}$ computing system composed of several simple, highly interconnected processing elements that process information through their dynamic state response to external inputs." The networks are widely applicable in solving classification and optimization problems, predictions, pattern recognition, etc. Because ANNs are adaptable, they can imitate linear and nonlinear relationships since the data are divided into various layers, making them well generalizable. These are trained using the datasets defined for training and then further used to predict the output values with the help of different algorithms (Figure 6) [4, 5]. 
TABLE 1: Comparison of materials with the pin-on-disc wear test and the results observed.

Materials used
The unreinforced portion was made of aluminum alloy
(Al-2014). Various SiC particles were added to the Al
alloy as a reinforcing substance.
AZ91D alloy
1. Nylon gears
2. Acetal gear pairs
A substrate made of BBS: LM 11 alloys was used, which
was reinforced with (a) SiC particles and (b) SiC fibers
for producing composites.
Glass fiber-reinforced polyphenylene sulfide polymers
APK polymer
POM polymer
UHMWPE polymer
PA66 polymer
147 Al alloy matrix composite containing the
following:
1. $10 \%$ B4C
2. $15 \%$ B4C
3. $20 \%$ B4C
4. 4147 Al/SiC composite

Aluminum syntactic foam

Untreated G3500 cast iron and S0050A cast steel Treated G4TG3500 cast iron and TS0050A cast steel

1. AA6061 alloy

2. AA $6061+20$ vol. $\%$ Saffil

3. AA6061 + 20 vol. $\%$ SiCp

4. AA6061 + 11 vol. $\%$ Saffil $+20 \%$ SiCp

5. AA6061 + 60 vol. $\% \mathrm{SiCp}$

1. PEEK

2. PEK

3. PEKK

1. Alloy 2014

2. Alloy 2024

3. Cast alloy 201 containing $\mathrm{Al} 2 \mathrm{O} 3$ and $\mathrm{SiC}$

1. Grey cast iron

2. A356/25SiCp aluminum metal matrix composite

1. $\mathrm{Al}$

2. $\mathrm{Al}+10 \mathrm{SiC}$

3. $\mathrm{Al}+20 \mathrm{SiC}$

4. $\mathrm{Al}+30 \mathrm{SiC}$

5. $\mathrm{Al}+40 \mathrm{SiC}$

Ti-6Al-4V alloy without thermal oxidation and Ti-6Al$4 \mathrm{~V}$ alloy with thermal oxidation

1. Al-SiC-Gr composites

2. Al-SiC composites

Commercially available pure $\mathrm{Al}$ and aluminumscandium alloy

Tests performed

Pin-on-disc wear test

Pin-on-disc

Pin-on-disc

Pin-on-disc

Pin-on-disc

Pin-on-disc

Pin-on-disc test

1. Pin-on-disc test

2. Abrasion test on rubber wheels

Pin-on-disc

Pin-on-disc

Pin-on-disc

Pin-on-disc

Pin-on-disc

Pin-on-disc

Results observed

With the increase in grain size, weight loss was observed to increase. It was discovered that composites [16] with larger particle sizes had better wear resistance. Due to the relative motion of AZ91D and stainless steel, frictional heat is generated, which affects the rate of wear.

The acetal gear pair has a higher wear rate than the nylon gear pair. Each acetal gear pair has a sliding speed threshold above which the wear rate dramatically increases.

The wear rate of the base alloy with no reinforcements was the highest, while the composites had the lowest wear rate. Because of a solid particle-matrix interface, the alloy reinforced with $\mathrm{SiC}$ particles had a low wear rate, whereas the alloy reinforced with $\mathrm{SiC}$ fibers had a higher wear rate due to a weak fiber-matrix interface.

A constant rate of steady-state wear was observed. POM polymer observed the highest wear out of all. It [20] had the highest wear rate across all sliding distances.

Due to stronger $\mathrm{SiC}$ particle binding to the alloy matrix, $\mathrm{Al} / \mathrm{SiC}$ matrix alloys outperformed AL/B4C alloys in terms of wear resistance.

The wear rate decreased as the sliding velocity increased.

Despite its porous nature, this material showed strong wear resistance.

Untreated and treated cast iron outperformed untreated cast steel in wear resistance.

Both EPN-treated substrates outperformed untreated substrates in terms of wear resistance.

Weight loss was found to decrease as the volume percent of the reinforcement was increased.

Wear resistance was highest in the 60 percent $\mathrm{SiCp}$ composite.

A linear increment in wear volume was observed with sliding distance and sliding load increase.

Wear resistance was higher in aluminum matrices with a high weight percent with no metallic component. SiC-containing alloys showed a substantial change. MMCs have a slightly lower wear rate than grey cast iron.

Resistance to wear for Al-SiC MMC is reported to be more significant than that to $\mathrm{Al}$; with an increase in reinforcement volume, wear resistance reportedly increased.

The handled specimen has shallower and thinner wear tracks than the untreated alloy.

$\mathrm{Al}-\mathrm{SiC}$ composites displayed lower resistance to wear than Al-SiC-Gr hybrid composites.

The aluminum-scandium alloy outperformed the pure industrial alloy in terms of wear resistance. 
TABle 1: Continued.

\begin{tabular}{|c|c|c|c|}
\hline Materials used & Tests performed & Results observed & Ref. \\
\hline $\begin{array}{l}\text { 1. PEEK } \\
\text { 2. } 20 \text { wt. } \% \text { GF-PEEK } \\
\text { 3. } 30 \text { wt. } \% \text { GF-PEEK } \\
\text { 4. } 30 \text { wt. } \% \text { CF-PEEK }\end{array}$ & Pin-on-disc & $\begin{array}{c}\text { According to the pin-on-ring sliding test, PEEK has a } \\
\text { higher wear resistance than other thermoplastics. } \\
\text { Carbon fibers outperformed glass fibers in terms of } \\
\text { wear resistance. }\end{array}$ & [32] \\
\hline Al-7Si alloy reinforced with the following: & & & \\
\hline $\begin{array}{l}\text { 1. } 0 \text { wt. } \% \\
\text { 2. } 5 \text { wt. } \%\end{array}$ & Pin-on-disc & $\begin{array}{l}\text { The wear rate decreased with an increase in TiB2 } \\
\text { content in the alloy. }\end{array}$ & [33] \\
\hline 3. 10 wt.\% TiB2 & & & \\
\hline $\begin{array}{l}\text { 1. Mg-9Al } \\
\text { 2. Mg-9Al with SiC-reinforced composite }\end{array}$ & Pin-on-disc & $\begin{array}{c}\text { Due to high load-bearing capacity, the composite } \\
\text { displayed significant wear resistance. }\end{array}$ & {$[34]$} \\
\hline Brushes made of copper and graphite & $\begin{array}{l}\text { Wear test with a } \\
\text { pin-on-slip ring }\end{array}$ & $\begin{array}{l}\text { Under } 30 \mathrm{kPa} \mathrm{BSP} \text {, arc erosion wear was the dominant } \\
\text { wear process; abrasion wear was dominant above } \\
\qquad 120 \mathrm{kPa} \text { BSP. }\end{array}$ & [35] \\
\hline 18 polymers were examined & Pin-on-disc & $\begin{array}{l}\text { PA 66-PTFE, POM-PTFE, PETP-PTFE, and PEEK- } \\
\text { PTFE may be used in dry air. } \\
\text { PA 66, PA 66-PTFE, and POM are the best materials for } \\
\text { use in water. }\end{array}$ & [36] \\
\hline
\end{tabular}

TABLE 2: Comparison of materials with the block-on-ring wear test and the results observed.

\begin{tabular}{|c|c|c|c|}
\hline Materials used & $\begin{array}{c}\text { Tests } \\
\text { performed }\end{array}$ & Results observed & Ref. \\
\hline $\begin{array}{l}\text { In one experiment, the NiCrBSi castellan PE } 3309 \text { alloy was } \\
\text { flame sprayed onto prism-shaped grey cast iron, and in } \\
\text { another, the alloy was laser remelted. }\end{array}$ & $\begin{array}{l}\text { Block-on- } \\
\text { ring test }\end{array}$ & $\begin{array}{l}\text { The laser remelted coating wore out faster. The most } \\
\text { common wear mechanism discovered is adhesion. }\end{array}$ & {$[42]$} \\
\hline $\begin{array}{l}\text { The substrate is grey cast iron, and the coating material is } \\
\text { NiCrBSi alloy powder. }\end{array}$ & $\begin{array}{l}\text { Block-on- } \\
\text { ring test }\end{array}$ & $\begin{array}{l}\text { Sliding speed had little to no effect on the wear rate as } \\
\text { observed during the sliding test. } \\
\text { Adhesive wear was observed at the highest loads. }\end{array}$ & [43] \\
\hline $\begin{array}{l}\mathrm{Al} \text { coated with a polyetheretherketone (PEEK) composite } \\
\text { and } \mathrm{Al} \text { coated with a polyetheretherketone/SiC }(\mathrm{PEEK} / \mathrm{SiC}) \\
\text { composite }\end{array}$ & $\begin{array}{l}\text { Block-on- } \\
\text { ring test }\end{array}$ & $\begin{array}{l}\text { Compared to aluminum substrates, both polymer } \\
\text { coatings showed a substantial improvement in wear } \\
\text { resistance. In most sliding conditions, the addition of } \\
\text { SiC to polymer coatings improved wear resistance even } \\
\text { further. }\end{array}$ & {$[44]$} \\
\hline WC-Co cemented carbides & $\begin{array}{l}\text { Block-on- } \\
\text { ring test }\end{array}$ & $\begin{array}{l}\text { As the binder content of the WC-Co alloys increased, } \\
\text { the wear rate caused by slipping increased. }\end{array}$ & {$[45]$} \\
\hline
\end{tabular}

TABLE 3: Comparison of materials with abrasive wear tests and the results observed.

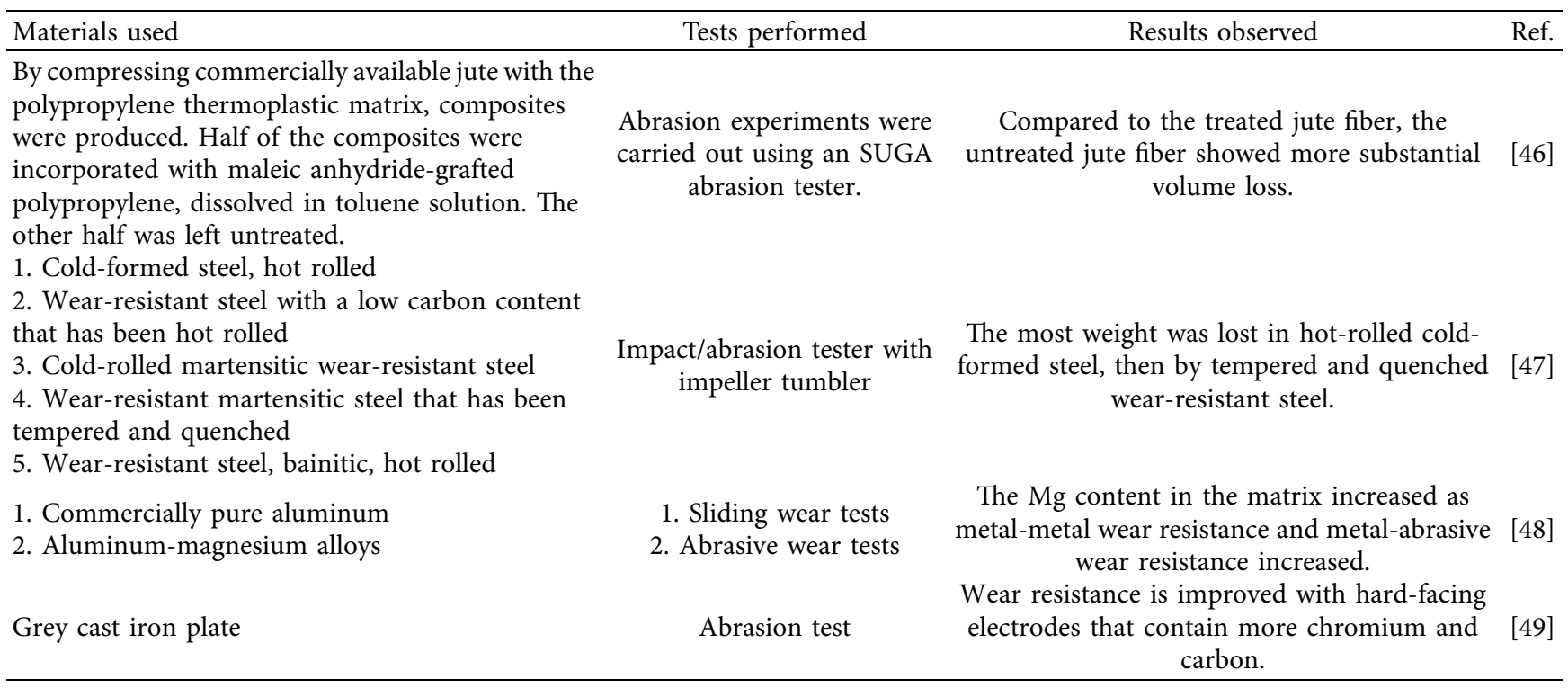


TABLE 3: Continued.

\begin{tabular}{ll}
\hline Materials used & Tests performed
\end{tabular}
Results observed

WC-Co powders used were as follows:

1. 17 wt.\% Co and 83 wt.\% WC

2. 15 wt.\% Co and 85 wt.\% WC

Composites used were as follows:

1. Carbon/epoxy

2. Glass/epoxy

3. Aramid/epoxy

4. Aramid/polyetheretherketone

5. Carbon/polyetheretherketone

Three plasma-sprayed coatings:

1. $\mathrm{Al} 2 \mathrm{O} 3$

2. $\mathrm{Al} 2 \mathrm{O} 3-13 \% \mathrm{TiO} 2$

3. $\mathrm{Cr} 2 \mathrm{O} 3$ (with NiCoCrAlY bond coat)

Two HVOF-sprayed cermet coatings:

1. WC- $17 \%$ Co

2. WC- $10 \%$ Co- $4 \%$ Cr
Abrasion test

Abrasion test

1. Dry sliding experiments with a ball on a disc

2. Test on a dry sand-steel wheel
Traditional powder-sprayed coating has a lower wear rate than HVOF-sprayed WC-Co coating.

A polyetheretherketone matrix is reinforced by oriented aramid and carbon fibers parallel to the surface.

The composite was stated as a low-wear composite material.

Plasma-sprayed ceramics displayed better results than HVOF coatings in dry particle abrasion conditions.

The plasma-sprayed $\mathrm{Cr} 2 \mathrm{O} 3$ and HVOF-coated ceramics displayed the best results in the pinon-disc test.

TABLE 4: Comparison of materials with the corrosion wear test and the results observed.

\begin{tabular}{|c|c|c|}
\hline Materials used & Tests performed & Results observed \\
\hline $\begin{array}{l}\text { 1. AISI } 1045 \text { steel with HVOF cermet } \\
\text { coating } \\
\text { 2. AISI } 1045 \text { steel with a hard }\end{array}$ & $\begin{array}{l}\text { Tribocorrosion } \\
\text { tests }\end{array}$ & $\begin{array}{l}\text { HVOF-coated materials outperformed hard chromium-coated steel in } \\
\text { terms of wear resistance. }\end{array}$ \\
\hline
\end{tabular}

1. AISI 1045 steel with HVOF cermet

chromium coating

TABLE 5: Comparison of materials with other types of wear tests and the results observed.

\begin{tabular}{|c|c|c|c|}
\hline Materials used & Tests performed & Results observed & Ref. \\
\hline $\begin{array}{l}\text { Epoxy resin } \\
\text { Carbon nanotubes }\end{array}$ & 3all-on-prism tribometer & Wear resistance was improved when CNTs were combined with an EP matrix. & {$[38]$} \\
\hline Cemented carbide tools & Disc turning test & $\begin{array}{c}\text { The most prevalent wear mechanisms observed were built-up edge, adherent } \\
\text { layer, and diffusion. }\end{array}$ & [39] \\
\hline $\begin{array}{l}\text { Nylon gears and acetal } \\
\text { gears }\end{array}$ & $\begin{array}{r}\text { Back-to-ba } \\
\text { configura }\end{array}$ & $\begin{array}{c}\text { The wear characteristics of nylon gears vary significantly from those of acetal } \\
\text { gears. }\end{array}$ & [40] \\
\hline $\mathrm{Ni}-\mathrm{SiC}$ composites & Ring-on-disc test & $\begin{array}{c}\text { With the increase in the percentage of } \mathrm{SiC} \text {, the wear resistance of the } \\
\text { deposited layer increases. }\end{array}$ & [41] \\
\hline
\end{tabular}

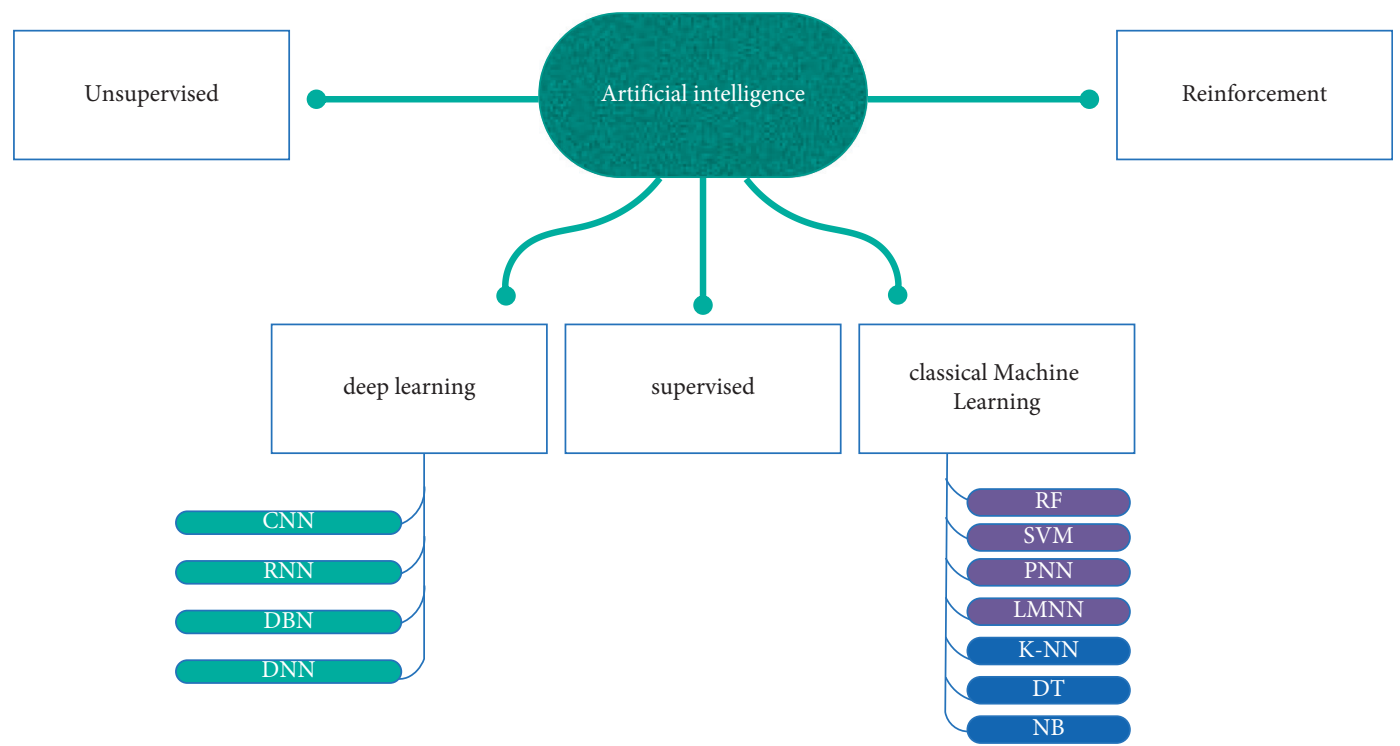

Figure 6: AI models: taxonomy. 
TABLE 6: Algorithms used for evaluation of wear behavior in different metals.

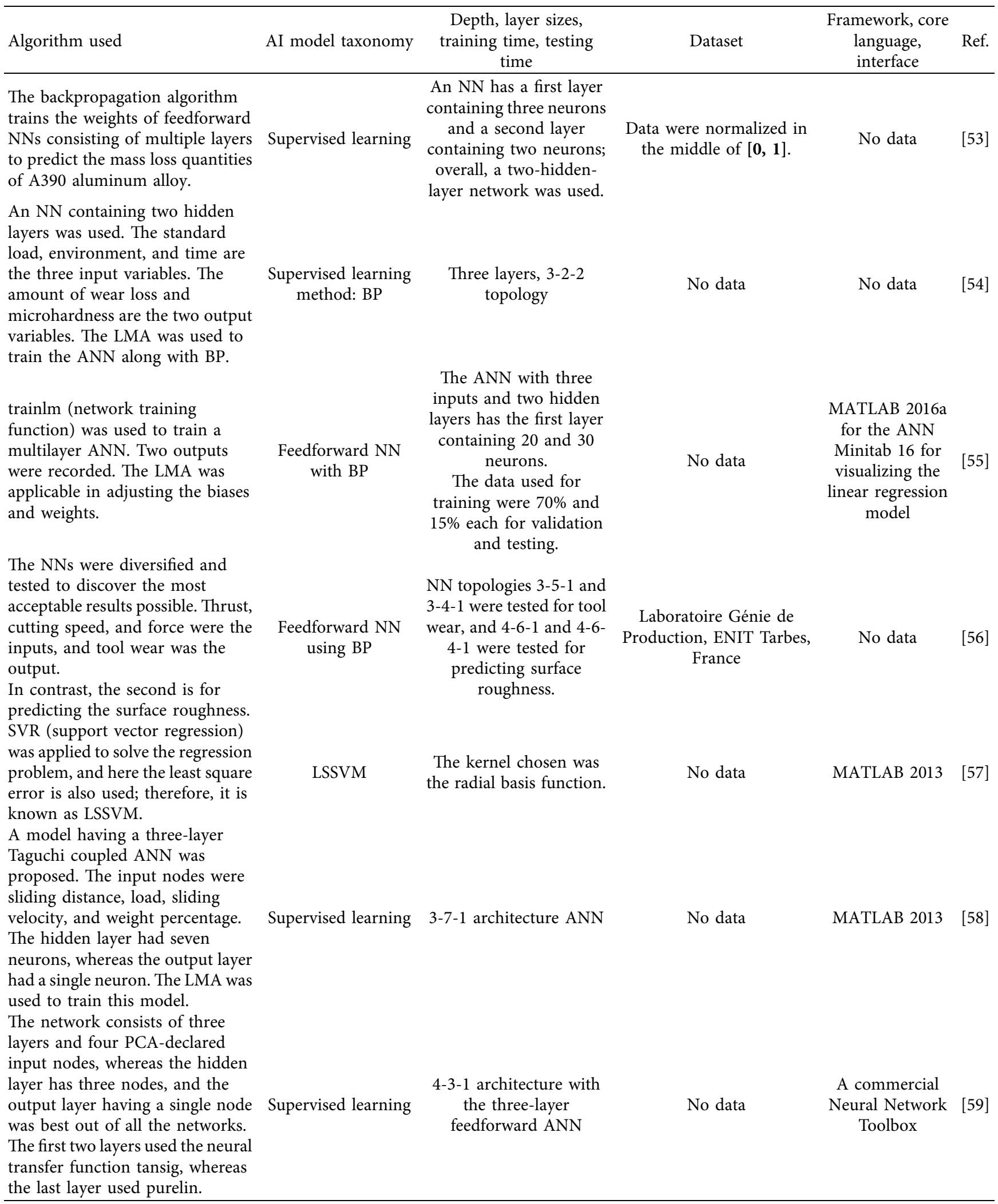


TABle 6: Continued.

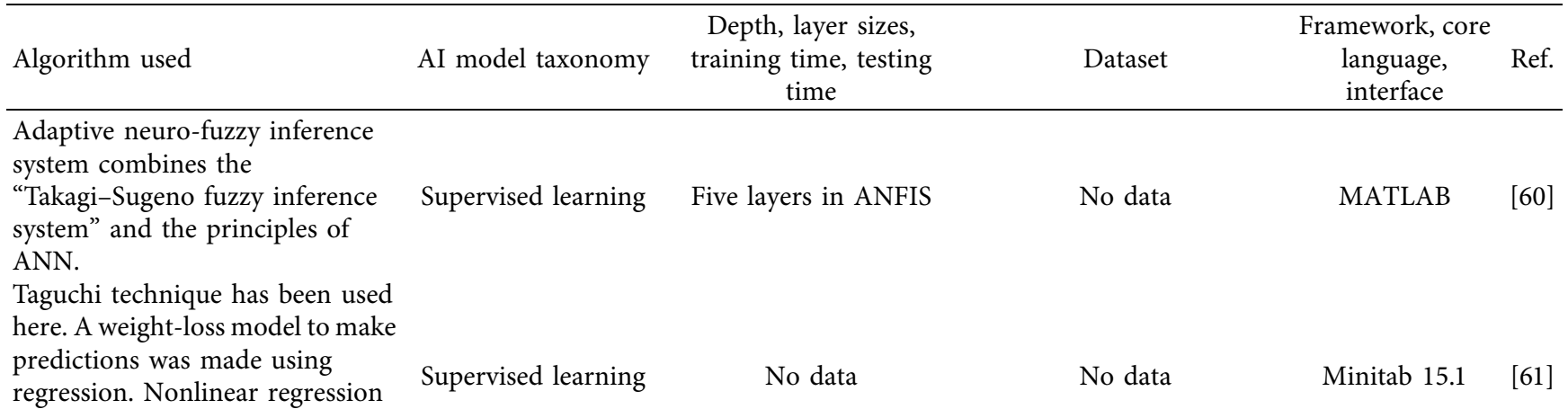
was used to correlate control factors and weight loss.

The AI algorithms used here are random forests, regression trees, MLP, and RBF.

"Kohonen's self-organizing map" was used to evaluate the tool's working status. Also, a triangular membership function applied neuro-fuzzy and fuzzy logic. The "centroid method of defuzzification" was used to obtain the flank wear.

One neuron represents each input parameter distinctively related to the coefficient of friction.

The input variables include applied load, sliding velocity, sliding distance, and material type, whereas the output is the coefficient of friction. It has 4-6-41 architecture. An MLP model was applied here because of its feedforward nature.

For evaluating the tool wear, a developed configuration system was applied. Also, using an expert system at different wear states helped clarify the output values of ANN.

The network used in this study was a generalized feedforward network. Input parameters were sliding time, sliding speed, load, and $\mathrm{Al}-\mathrm{Si} \%$, whereas the output parameter was specific wear rate. The network consisted of three hidden layers with 16,8 , and 5 neurons.

The first two layers used the TanhAxon function, whereas the last layer applied the BiasAxon function.
Supervised learning: RBF has one layer, and MLP, RBF, and random forests

Supervised learning: backpropagation NN

2-3-1 architecture

Supervised learning: MLP

Unsupervised

learning: ART2

Number of input neurons in SOM: 15, and number of neurons in an

SOM layer: 36

4-11-5-1 architecture and two hidden layers Supervised learning with four inputs and one output layer were applied.
The experimental data were collected to provide a broad number of wear conditions and processing times while acquiring data on the power drive for a fixed machining process-the face milling of carbonquality structural steel 45 .

The training data for the networks were collected through experimental studies.

No data

No data

No data

No data

No data

No data

No data 
TABle 6: Continued.

\begin{tabular}{|c|c|c|c|c|}
\hline Algorithm used & AI model taxonomy & $\begin{array}{l}\text { Depth, layer sizes, } \\
\text { training time, testing } \\
\text { time }\end{array}$ & Dataset & $\begin{array}{c}\text { Framework, core } \\
\text { language, } \\
\text { interface }\end{array}$ \\
\hline
\end{tabular}

The LMA along with BP was applied in this study. Load and speed are the two nodes of the input layer, whereas the friction and mass loss coefficient are the two nodes of the output layer. The minimal fault was observed in the output due to ten neurons in the hidden layer.

The proposed reduction model here is a combination of POD and Supervised learning RBF.

The ANN was trained with the Levenberg-Marquardt algorithm (LMA), Bayesian regulation (BR), resilient backpropagation (RP), scaled conjugate gradient (SCG), and gradient descent (GD).

Supervised learning

The ANN and Sugeno FIS have been applied, and BP having 4-3-1 Supervised learning: architecture and LMA is adopted backpropagation here.

FZM and ANN, along with a neuro-fuzzy ANFIS, are adopted here.

The Elman-inspired RNN was applied. The sensor uses the relationship between the variables to be measured and the power consumption.

RF, MLP, RBF, etc., were used in this study to predict surface roughness and mass loss.

Output, i.e., tool wear, is predicted with the help of residual errors as the basis of decision-making.

Volume loss is predicted using LR, SVM, ANN, and other extreme learning methods.

Supervised learning

Supervised learning: backpropagation for ANN

Unsupervised learning for fuzzy cmeans clustering

\section{Bayesian} regularization regression trees,

MLP BP

Supervised learning: MLP

Supervised learning: ANN, SVR, and LR
Two output and ten hidden neurons

No data

MATLAB

The network consists of two layers, one with RBF neurons and the other with output neurons.

Five distinct training algorithms were used, along with eighteen different architectures.

The Bayesian algorithm trained in a two-layered neural network has reached the best results (26 105 1).

The network has 4-3-1 architecture and one hidden layer.

Supervised learning:
The ANN having 4-3-1 architecture and ninetycluster C-mean

clustering gave the best performance.

The best model HU55 implies five hidden units and a delay of 5 .

A network having a three-layer architecture and a hidden layer used.

MLP has 6-12-1

architecture, and one hidden layer was used here. architecture and a quadratic function as the SVR kernel, whereas ELM used here is a feedforward NN having a single hidden layer. consisting of RBF was

The ANN has a 3-4-1
No data

MATLAB

Training data were obtained by 360 randomly distributed data collected from testing of four friction materials.

Training data were acquired by testing eight different friction materials, only predicting fade performance.

No data

MATLAB

R2015a using NN Toolbox

A Training and Test Data Set (TTDS) is generated with a specific combination of the grinding experiments collected.

No data

No data

Experimentally obtained data

MATLAB
MATLAB
No data

MATLAB 
TABLE 6: Continued.

\begin{tabular}{|c|c|c|c|c|c|}
\hline Algorithm used & AI model taxonomy & $\begin{array}{c}\text { Depth, layer sizes, } \\
\text { training time, testing } \\
\text { time }\end{array}$ & Dataset & $\begin{array}{c}\text { Framework, core } \\
\text { language, } \\
\text { interface }\end{array}$ & Ref. \\
\hline $\begin{array}{l}\text { Supervised learning methods such } \\
\text { as SVR, RF regression, decision } \\
\text { tree regression, GBR, GPR, MLP, } \\
\text { and KNN are used. }\end{array}$ & Supervised learning & $\begin{array}{l}\text { SVR uses an RBF for the } \\
\text { kernel. } \\
\text { MLP having five hidden } \\
\text { layers and ten neurons in } \\
\text { each layer with ReLU } \\
\text { activation was used here. }\end{array}$ & $\begin{array}{l}\text { Collected from } 13 \\
\text { references of 316L SS parts } \\
\text { processed by SLM }\end{array}$ & $\begin{array}{l}\text { Python } \\
\text { TensorFlow, } \\
\text { scikit-learn, } \\
\text { Google Colab }\end{array}$ & {$[76]$} \\
\hline $\begin{array}{l}\text { The ANN with BP is applied along } \\
\text { with ANOVA to decide the } \\
\text { potential parameters to predict } \\
\text { the specific wear rate reduction. }\end{array}$ & Supervised learning & $\begin{array}{l}\text { The ANN has the } 2: 5: 1 \\
\text { architecture with } \\
\text { sigmoid activation. }\end{array}$ & No data & $\begin{array}{c}\text { Python, Minitab } \\
19\end{array}$ & {$[77]$} \\
\hline $\begin{array}{l}\text { Analysis of the erosion process is } \\
\text { done using the ANN model along } \\
\text { with LMA. }\end{array}$ & Supervised learning & $\begin{array}{l}\text { The network having } \\
\text { three layers and } 2-6-3 \\
\text { architecture is used here. }\end{array}$ & No data & $\begin{array}{l}\text { MATLAB 2017a } \\
\text { Neural Network } \\
\text { Toolbox }\end{array}$ & {$[78]$} \\
\hline $\begin{array}{l}\text { ANN and RSM models were } \\
\text { compared based on their } \\
\text { predictive capacity of wear } \\
\text { behavior of fabricated composites. }\end{array}$ & Supervised learning & $\begin{array}{l}\text { Three inputs, ten hidden } \\
\text { layers, and two outputs }\end{array}$ & No data & MATLAB & [79] \\
\hline
\end{tabular}

TABLE 7: Advantages and disadvantages of the above-discussed algorithms (Table 6) used to evaluate wear behavior in different metals.

Advantages
NNs are quite endurable as the parameter (weight) values are
changed according to the performance. The modifications are
made according to an ML algorithm called gradient descent
(GD).
The model was concluded to be excellent and fast because of
the little prediction time, and the results of the ANN model,
along with the experimental study, indicated the same. Also,
the LMA was faster than GD or GN.
The experiment helped perceive the most influential factors
affecting the friction coefficient and the wear rate. Therefore,
the ANN is very much capable of predicting the same.

NNs can take in linear and nonlinear relationships, generating and performing well to show good results.

LSSVM could eliminate local minima. Also, comparing the relative error of RSM and LSSVM, the graph depicts LSSVM as a suitable model since it has fewer relative errors.

To obtain an optimal value of the input parameter and achieve an output value with the minor target, Taguchi coupled ANN was applied.

The ANN was better than a statistical approach since it has three times lower relative mean error and higher stability for all studied conditions.

The aim behind ANFIS is to connect inputs and outputs accurately. It could help set up a model with uncertainties and composite data distribution.

To determine parameters having minimum variations, Taguchi methods were helpful. Also, ANOVA was used to check the quality of features affected by design parameters.

RF showed the highest precision. Due to its ability to get tuned and give visual information, RF can be directly used by product engineers.

To improve user-friendliness, linguistic rules were applied. Also, for fuzzy logic, they act as an advantage.
Disadvantages

Ref.

Other algorithms like SVM in [56] could be implemented and

compared for better performance and results. For example, the

LMA (Levenberg-Marquardt algorithm) could improve the model instead of GD.

The LMA gives us only the local optimum instead of the global optimum.

Because the derivatives of the flat functions do not exist after a certain point in time, the algorithm might be a failure.

The LMA might not be a potential choice if the beginning point does not have the right quality, i.e., distant from the actual required values.

Sigmoid (the activation function) was not zero-centered that could give undesired results and implications during the implementation of GD. An alternative for it could be tanh, and where priority is speed, ReLU would be suitable.

SVM underperforms if the number of characteristics for a data point exceeds the number of training data samples. Therefore, a considerable amount of data are required to be enforced.

The effects of a parameter on the resultant value were not precise.

Also, the method did not provide any absolute results; therefore, it was stated unsuitable for a constantly changing process.

A model without units makes the equations incomprehensible

physically; therefore, it is necessary to include units to make sense in [59] the world.

The limitations of ANFIS are the computational expense, and it is hard to compute large input values. Therefore, it cannot be used in a big data paradigm.

The effects of a parameter on the resultant value were not precise.

Also, the method did not provide any absolute results; therefore, it [61] was stated unsuitable for a constantly changing process.

The RF creates many trees and needs a lot of computational power and colossal training time.

Overfitting of noisy data may lead to unfavorable outputs.

To achieve a stable mapping with the help of Kohonen's SOM, the nearby data point needs to behave similarly. 
TABLE 7: Continued.

Advantages
The ANN aids in estimating the coefficient of friction for
parameter values more significant than those included in POD
experiments.
An ANN and expert systems were used to find the worn-out
tools. A blend of inference results and complex sensor outputs
helped achieve a positive result.
GFs usually take in more compound, nonlinear, and
unpredictable relationships since their connections can skip
several layers.
ANN's characteristics like adaptability and fault tolerance are
beneficial here.
The unknown parameters can be found through this technique
if the outputs are already known.
Less period is required for training the Bayes, and its
application is effortless.

Results were in order with the experimental values; therefore, the neuro-fuzzy approach is good.

A framework based on the Takagi-Sugeno neuro-fuzzy network has proven to be the best of both worlds.

The RNN can mimic the dynamic nature of the problem here as the old network values are reused, in turn, giving the ANN memory.

$\mathrm{RF}$ is concluded to be best for industry purposes as no parameter tuning was required for it. Also, its predictions are equally good as MLPs.

This model practices a high-powered working nature, whereas a supervision system cannot.

An R2 error value of 0.989 was obtained using the ELM

method, and a reduced number of tests, testing time, and cost were also observed here.

GBR was concluded as the best out of the seven ML algorithms compared here since it resulted in the slightest standard deviation and good accuracy.

Minimum error artificial data were generated for processing, and the method used here is flexible and considered best for evaluating the tribo-parameters.

The ANN investigated the impact on the APS process parameters well.

A regression coefficient value of 0.99996 using the ANN was the best of all the other proposed models.

(1) ANNs typically have three main layers. Input layer: The layer to which input data and patterns are fed is always a single input layer.

(2) Hidden layers: There could be several of these layers. Behind the scenes, processing occurs, and the output is calculated based on "weights," which determine the significance of a specific characteristic. These layers also remove inessential data from the input data before sending them to the hidden layer, next in line for processing.

(3) The endmost hidden layer is linked to the output layer, which provides the final output value(s).

The center of NNs is backpropagation. It is an algorithm through which the neural network corrects itself with each iteration that relies on weights.
Increasing the total number of parameters in an MLP might lead to more time. It is inefficient as such high dimensions might be redundant.

Expert systems collapse without a proper output from the ANN; therefore, they will face issues classifying the tool's wear.

A network of this kind could overfit due to its inability to deduce the latest data when applied to simple tasks.

The beginning point is far off the desired value; the LMA might not perform well here.

Massive space for inputs is required when using RBF though it is not favorable to waste inputs while having other essential tasks.

The nature of the attributes is presumed to be mutually independent in the Bayesian algorithm, but that seems impossible as the

predictors cannot be fully independent.

ovided no output membership function, and chances of loss of interpretability are high.

Massive inputs and computational expenses are some of the limitations of ANFIS. Therefore, it is not applicable for a "big data paradigm."

There can be problems with the gradient not converging. It is a complex task while working with tanh or ReLU activation functions.

The RF creates several trees; therefore, it requires more computational power and more training time.

Chances of noisy overfitting data having unfavorable outputs as results are there.

A neuro-FIS might be applicable in such a dynamic environment.

More training cases could lead to the loss of the essence of the problem as the ELM consists of only one hidden layer. This was not observed here since the number of cases is only 40 .

KNN, STR, and GPR will not be recommended as they are considered the worst-performing algorithms here.

The work is limited to the general behavior of distinct reinforcement particles due to the variable metallurgical properties.

Future work includes the optimum coating properties dependent on the APS process parameters.

Different algorithms could be used for training the ANN along with GBR and SVR, and it can be used to compare the results.

\section{Summary and Conclusions}

The research works discussed briefly in this review propose various systems for supervising the machining process, tool wear monitoring, determination of wear state for a tool, and many more. Significant research has been done involving ANNs with the LVM (as shown in Tables 6 and 7) algorithm training the models, resulting in highly generalized and fault-tolerant models; however, LVM can only provide a local optimum and may not respond to flat functions, producing unwanted results, and the starting point is way far from the optimal.

Some studies consider the ANFIS, adaptive neuro-fuzzy interface system, method that combines ANN and fluidic logic, specifically the "Takagi-Sugeno fuzzy interference system," which can capture neural networks fumigating logic 
in one. However, this model may not perform well for many inputs, i.e., this model fails in a big data paradigm. The surface roughness and wear were predicted using RNNs, i.e., ANNs having memory; hence, they are more suitable for a constantly developing environment of such wear behavior of tools. Surface wear was detected using random forests and multilayer perceptrons based on surface isotropy levels. Random forests are superior because MLPs require parameter tuning, and their output is nearly identical to that of RFs. These methods for various processes are also discussed in some research that encompasses most of the approaches [80-92].

6.1. Accuracies Achieved in Recent Research Works. Using a two-hidden-layer neural network, Kumar and Singh [53] obtained a normalized standard error of 0.00085 . At the same time, Çetinel et al. [54], who also used a two-hiddenlayer network but with the addition of the Levenberg-Marquardt algorithm, found an average error of $2.461 \%$ for wear (in micrometers) and $0.245 \%$ error for microhardness (in $\mathrm{HV}$ ). A least square support vector machine to predict wear behavior in [56] yielded an average of 1.2 percent better results on 52 runs than the RSM model. Kolodziejczyk [58] used PCA preprocessing and the LVM algorithm to achieve a mean relative error of 1.8 percent, three times lower than that in previous studies. A multilayer perceptron model was used in [64], which yielded 0.0186 and 0.0180 training and testing residual errors, respectively. The SOM model had a higher correlation coefficient than the ART2 model in [65], with 0.964 and 0.946 for the training and test sets. The ANN was combined with the Taguchi method in [55], and a 99.5 percent confidence level was observed between predicted and actual wear rates and coefficients of friction. In [93], the ANN with one hidden layer had a more significant sum of squares error (SSE) of 0.025 and 0.25 for training and testing, respectively, whereas the ANN with two hidden layers had 0.008 and 0.46 SSEs for training and testing. As a result of the lower SSE, the twohidden-layer networks were chosen, with an RMSE of 2.64 percent on average. The ANFIS models-sigmoidal, triangular, Gaussian, and bell-shaped MFs - were used [59]. The most accurate model was sigmoidal MF, which had a regression coefficient of 0.96775 . RFs and MLPs were used in [62], with RFs having a better accuracy of 33 to 44 percent and an error of 0.2457 micrometers than the MLP's 0.4139 . An ANFIS was used for various membership functions [70]. The RMSE was in the order of E-11, which was 0.557 for the ANN. The Sugeno-type ANFIS model had the best correlation coefficient of 97.74 percent with gbellmf membership. Nagaraj and Gopalakrishnan [66] reported an MSE of 0.0904 and an MAE of 0.1257. In [73], various ML techniques model various parameters, with MLPs better in 3/4 of them and RFs taking one of the parameters. MLPs were found to have a 52 percent accuracy rate. The ANFISs appear to have the least amount of error.

6.2. Open Issues. Multiple systems have been proposed in recent research to address the supervision process in machining, tool wear monitoring, tool wear detection, and so on. More researchers use ANNs with the LVM algorithm to train fault-tolerant and well-generalized models, but the LVM only provides a local optimum and may not work for flat functions. If the starting point is too far from the optimal, it may also produce undesirable results. The ANFIS, adaptive neuro-fuzzy interface system, is a combination of ANN and fuzzy logic used in a few papers, specifically the Takagi-Sugeno fuzzy interference system, which can capture the essence of both neural nets and fuzzy logic in one [94-102]. However, this model may not work well for many inputs, i.e., this model fails in a big data paradigm. RNNs, which are technically ANNs with memory and thus more suited for such ever-changing dynamic environments as tool wear, were also used to predict wear and surface roughness [103-106]. Surface wear was also predicted using random forests and multilayer perceptrons and surface isotropy levels. MLPs require parameter tuning, and their output is nearly identical to that of RFs, so random forests are preferable. These various processes are also discussed in [107], which encompasses most approaches.

6.3. Future Directions. Wear analysis using artificial intelligence is a relatively new concept. Formal result: Accordingly, it was discovered that there is less work on AI than aluminum (e.g., FGP grey-coated or NiCrBSi-coated aluminum) writable composites (e.g., polymer-reinforced glass), which indicates that it is to be expected since less work has been done on AI (e.g., plastic/FGP-NiCr alloyed glass) to grasp fully $[80,108]$.Further study is required to understand the full capabilities of using AI. This state-of-the-art technology for analyzing artificial neural networks is now being utilized for efficient and economical wear-resistant materials. Tool wear is one of the most common aspects of the machining process that needs to be analyzed. Research can be done on the tool metal's wear behavior in the future, and the metal can be modified and tested for wear. New research opportunities can be found to find an ideal metal for machining processes. Artificial neural networks for wear analysis can help identify the most efficient coating materials for various substrates to increase the substrate's wear resistance with accurate predictions, which is inefficient and time-consuming when identified using traditional methods. Artificial intelligence is currently limited to analyzing wear for various materials used in manufacturing and production. Still, the main benefit of using AI is studying a wide range of data and making accurate predictions. More experimentation is needed to make the most of this technology, which will allow industries to predict the time and type of wear that will occur on a material ahead of time, allowing them to continue operating without interruption [108-114].

\section{Abbreviation}

ANN: Artificial neural network

NN: Neural network

ML: $\quad$ Machine learning

GD: Gradient descent

LMA: Levenberg-Marquardt algorithm 
BP: Backpropagation

GN: Gaussian network

SVR: Support vector regression

LSSVM: Least square support vector machine

RSM: $\quad$ Response surface methodology

RBF: Radial basis function

MLP: Multilayer perceptron

SOM: Self-organizing map

GF: $\quad$ Generalized feedforward

POD: Proper orthogonal decomposition

BR: Bayesian regulation

RP: Resilient backpropagation

SCG: $\quad$ Scaled conjugate gradient

FIS: $\quad$ Fuzzy inference system

FZM: $\quad$ Fuzzy clustering method

LR: Linear regression

ELM: $\quad$ Extreme learning method

RF: $\quad$ Random forest

GBR: Gradient boosting regression

GPR: Gaussian process regression.

\section{Conflicts of Interest}

The authors declare no conflicts of interest.

\section{Authors' Contributions}

Senthil Kumaran Selvaraj and Aditya Raj have Contributed Equally AR and SKS conceptualized the research idea and ran the software. SKS performed the methodology, validated the data, and administered the project. AR, MD, UC, IS, and $\mathrm{CK}$ were involved in formal analysis and wrote the original draft. AR, MD, and UC investigated the data and obtained the resources. AR, MD, UC, and IS curated the data. UC and $\mathrm{CK}$ visualized the data and reviewed and edited the paper. SKS and UC supervised the study. All the authors have read and agreed to the published version of the manuscript.

\section{References}

[1] "Standard terminology relating to wear and erosion," Annual Book of Standards, vol. 03.02, pp. 243-250, 1987.

[2] G. W. Stachowiak and A. W. Batchelor, Engineering Tribology, Elsevier Applied Science, Amsterdam, Netherland, 2014.

[3] F. Kara, M. Karabatak, M. Ayyıldız, and E. Nas, "Effect of machinability, microstructure and hardness of deep cryogenic treatment in hard turning of AISI D2 steel with ceramic cutting," Journal of Materials Research and Technology, vol. 9, no. 1, pp. 969-983, 2020.

[4] R. M. C. Karthik, R. L. Malghan, F. Kara, A. Shettigar, S. S. Rao, and M. A. Herbert, "Influence of support vector regression (SVR) on cryogenic face milling," Advances in Materials Science and Engineering, vol. 2021, Article ID 9984369, 18 pages, 2021.

[5] A. Eser, E. A. Ayyıldız, M. Ayyıldız, and F. Kara, "Artificial intelligence-based surface roughness estimation modelling for milling of AA6061 alloy," Advances in Materials Science and Engineering, vol. 2021, Article ID 5576600, 10 pages, 2021.

[6] P. Ganeshan, S. S. Kumaran, K. Raja, and D. Venkateswarlu, "An investigation of mechanical properties of madar fiber reinforced polyester composites for various fiber length and fiber content," Materials Research Express, vol. 6, 2019.

[7] S. Kannan, S. S. Kumaran, and L. A. Kumaraswamidhas, "Optimization of friction welding by taguchi and ANOVA method on commercial aluminium tube to $\mathrm{Al} 2025$ tube plate with backing block using an external tool," Journal of Mechanical Science and Technology, vol. 30, pp. 2225-2235, 2016.

[8] S. K. Senthil, S. Muthukumaran, and C. R. Chandrasekhar, "Effect of tube preparations on joint strength in friction welding of tube-to-tube plate using an external tool process," Experimental Techniques, vol. 37, pp. 24-32, 2013.

[9] V. V. Kumar and S. S. Kumaran, "Friction material composite: types of brake friction material formulations and effects of various ingredients on brake performance-a review," Materials Research Express, vol. 6, 2019.

[10] S. K. Senthil, S. Muthukumaran, D. Venkateswarlu, G. K. Balaji, and S. Vinodh, "Eco-friendly aspects associated with friction welding of tube-to-tube plate using an external tool process," Int J Sustain Eng, vol. 5, pp. 120-127, 2012.

[11] S. K. Senthil and A. D. Daniel, "Friction welding joints of SA 213 tube to SA 387 tube plate boiler grade materials by using clearance and interference fit method," Materials Today Proceedings, vol. 5, pp. 8557-8566, 2018.

[12] H. Unal, A. Mimaroglu, U. Kadıglu, and H. Ekiz, "Sliding friction and wear behaviour of polytetrafluoroethylene and its composites under dry conditions," Materials \& Design, vol. 25, no. 3, pp. 239-245, 2004.

[13] H. Piht1lı and N. Tosun, "Effect of load and speed on the wear behavior of woven glass fabrics and aramid fiber-reinforced composites," Wear, vol. 252, no. 11-12, pp. 979-984, 2002.

[14] G. Bregliozzi, A. Di Schino, S. U. Ahmed, J. M. Kenny, and H. Haefke, "Cavitation wear behavior of austenitic stainless steels with different grain sizes," Wear, vol. 258, no. 1-4, pp. 503-510, 2005.

[15] J. Zheng, Z. R. Zhou, J. Zhang, H. Li, and H. Y. Yu, "On the friction and wear behavior of human tooth enamel and dentin," Wear, vol. 255, no. 7-12, pp. 967-974, 2003.

[16] Y. Şahin, "Abrasive wear behavior of SiC/2014 aluminium composite," Tribology International, vol. 43, no. 5-6, pp. 939-943, 2010.

[17] N. N. Aung, W. Zhou, and L. E. Lim, "Wear behavior of AZ91D alloy at low sliding speeds," Wear, vol. 265, no. 5-6, pp. 780-786, 2008.

[18] A. R. Breeds, S. N. Kukureka, K. Mao, D. Walton, and C. J. Hooke, "Wear behaviour of acetal gear pairs," Wear, vol. 166, no. 1, pp. 85-91, 1993.

[19] O. P. Modi, B. K. Prasad, A. H. Yegneswaran, and M. L. Vaidya, "Dry sliding wear behaviour of squeeze cast aluminium alloy-silicon carbide composites," Materials Science and Engineering: A, vol. 151, no. 2, pp. 235-245, 1992.

[20] H. Unal, U. Sen, and A. Mimaroglu, "Abrasive wear behaviour of polymeric materials," Materials \& Design, vol. 26, no. 8, pp. 705-710, 2005.

[21] R. Ipek, "Adhesive wear behaviour of $\mathrm{B} 4 \mathrm{C}$ and $\mathrm{SiC}$ reinforced 4147 Al matrix composites (Al/B4C-Al/SiC)," Journal of Materials Processing Technology, vol. 162-163, pp. 71-75, 2005.

[22] D. P. Mondal, S. Das, and N. Jha, "Dry sliding wear behaviour of aluminum syntactic foam," Materials \& Design, vol. 30, no. 7, pp. 2563-2568, 2009.

[23] X. Nie, L. Wang, Z. C. Yao, L. Zhang, and F. Cheng, "Sliding wear behavior of electrolytic plasma nitrided cast iron and steel," Surface and Coatings Technology, vol. 200, no. 5-6, pp. 1745-1750, 2005. 
[24] A. B. Gurcan and T. N. Baker, "Wear behavior of AA6061 aluminium alloy and its composites," Wear, vol. 188, no. 1-2, pp. 185-191, 1995.

[25] A. P. Harsha and U. S. Tewari, "Two-body and three-body abrasive wear behaviour of polyaryletherketone composites," Polymer Testing, vol. 22, no. 4, pp. 403-418, 2003.

[26] F. M. Hosking, F. F. Portillo, R. Wunderlin, and R. Mehrabian, "Composites of aluminium alloys: fabrication and wear behaviour," Journal of Materials Science, vol. 17, no. 2, pp. 477-498, 1982.

[27] N. Natarajan, S. Vijayarangan, and I. Rajendran, "Wear behavior of A356/25SiCp aluminium matrix composites sliding against automobile friction material," Wear, vol. 261, no. 7-8, pp. 812-822, 2006.

[28] B. Venkataraman and G. Sundararajan, "The sliding wear behaviour of AlSiC particulate composites-I. Macrobehaviour," Acta Materialia, vol. 44, no. 2, pp. 451-460, 1996.

[29] H. Güleryüz and H. Çimenoğlu, "Effect of thermal oxidation on corrosion and corrosion-wear behavior of a Ti-6Al-4V alloy," Biomaterials, vol. 25, no. 16, pp. 3325-3333, 2004.

[30] S. Suresha and B. K. Sridhara, "Effect of addition of graphite particulates on the wear behaviour in aluminium-silicon carbide-graphite composites," Materials \& Design, vol. 31, no. 4, pp. 1804-1812, 2010.

[31] K. Venkateswarlu, L. C. Pathak, A. K. Ray et al., "Microstructure, tensile strength and wear behaviour of Al-Sc alloy," Materials Science and Engineering: A, vol. 383, no. 2, pp. 374-380, 2004.

[32] H. Voss and K. Friedrich, "On the wear behaviour of shortfibre-reinforced peek composites," Wear, vol. 116, no. 1, pp. 1-18, 1987.

[33] S. Kumar, M. Chakraborty, V. S. Sarma, and B. S. Murty, "Tensile and wear behavior of in situ Al-7Si/TiB2 particulate composites," Wear, vol. 265, no. 1-2, pp. 134-142, 2008.

[34] C. Y. H. Lim, S. C. Lim, and M. Gupta, "Wear behavior of SiCp-reinforced magnesium matrix composites," Wear, vol. 255, no. 1-6, pp. 629-637, 2003.

[35] I. Yasar, A. Canakci, and F. Arslan, "The effect of brush spring pressure on the wear behaviour of copper-graphite brushes with electrical current," Tribology International, vol. 40, no. 9, pp. 1381-1386, 2007.

[36] J. W. M. Mens and A. W. J. D. Gee, "Friction and wear behavior of 18 polymers in contact with steel in environments of air and water," Wear, vol. 149, no. 1-2, pp. 255-268, 1991.

[37] L. Fedrizzi, S. Rossi, R. Cristel, and P. L. Bonora, "Corrosion and wear behavior of HVOF cermet coatings used to replace hard chromium," Electrochimica Acta, vol. 49, no. 17-18, pp. 2803-2814, 2004.

[38] O. Jacobs, W. Xu, B. Schädel, and W. Wu, "Wear behaviour of carbon nanotube reinforced epoxy resin composites," Tribology Letters, vol. 23, no. 1, pp. 65-75, 2006.

[39] G. List, M. Nouari, D. Géhin et al., "Wear behavior of cemented carbide tools in dry machining of aluminium alloy," Wear, vol. 259, no. 7-12, pp. 1177-1189, 2005.

[40] K. Mao, W. Li, C. J. Hooke, and D. Walton, "Friction and wear behavior of acetal and nylon gears," Wear, vol. 267, no. 1-4, pp. 639-645, 2009.

[41] K. H. Hou, M. D. Ger, L. M. Wang, and S. T. Ke, "The wear behavior of electro-codeposited Ni-SiC composites," Wear, vol. 253, no. 9-10, pp. 994-1003, 2002.

[42] R. Gonzalez, M. Cadenas, R. Fernandez, J. L. Cortizo, and E. Rodríguez, "Wear behavior of flame sprayed $\mathrm{NiCrBSi}$ coating remelted by flame or by laser," Wear, vol. 262, no. 34, pp. 301-307, 2007.
[43] E. Fernández, M. Cadenas, R. González, C. Navas, R. Fernández, and J. D. Damborenea, "Wear behavior of laser clad NiCrBSi coating," Wear, vol. 259, no. 7-12, pp. 870-875, 2005.

[44] G. Zhang, H. Liao, H. Li, C. Mateus, J.-M. Bordes, and C. Coddet, "On dry sliding friction and wear behaviour of PEEK and PEEK/SiC-composite coatings," Wear, vol. 260, no. 6, pp. 594-600, 2006.

[45] J. Pirso, S. Letunovitš, and M. Viljus, "Friction and wear behavior of cemented carbides," Wear, vol. 257, no. 3-4, pp. 257-265, 2004.

[46] N. Chand and U. K. Dwivedi, "Effect of coupling agent on abrasive wear behaviour of chopped jute fibre-reinforced polypropylene composites," Wear, vol. 261, no. 10, pp. 1057-1063, 2006.

[47] A. Sundström, J. Rendón, and M. Olsson, "Wear behavior of some low alloyed steels under combined impact/abrasion contact conditions," Wear, vol. 250, no. 1-12, pp. 744-754, 2001.

[48] A. Hayrettin, K. Tolga, C. Ercan, and C. Huseyin, "Wear behavior of $\mathrm{Al} /(\mathrm{Al} 2 \mathrm{O} 3 \mathrm{p} / \mathrm{SiCp})$ hybrid composites," Tribology International, vol. 39, pp. 213-220, 2006.

[49] S. Chatterjee and T. K. Pal, "Wear behavior of hardfacing deposits on cast iron," Wear, vol. 255, no. 1-6, pp. 417-425, 2003.

[50] D. A. Stewart, P. H. Shipway, and D. G. McCartney, "Abrasive wear behaviour of conventional and nanocomposite HVOF-sprayed WC-Co coatings," Wear, vol. 225-229, pp. 789-798, 1999.

[51] M. Cirino, R. B. Pipes, and K. Friedrich, "The abrasive wear behaviour of continuous fibre polymer composites," Journal of Materials Science, vol. 22, no. 7, pp. 2481-2492, 1987.

[52] G. Bolelli, V. Cannillo, L. Lusvarghi, and T. Manfredini, "Wear behavior of thermally sprayed ceramic oxide coatings," Wear, vol. 261, no. 11-12, pp. 1298-1315, 2006.

[53] A. Kumar and D. Singh, "Artificial neural network-based wear loss prediction for A390 aluminium alloy," Journal of Theoretical and Applied Information Technology, vol. 4, no. 10, 2008.

[54] H. Çetinel, H. Öztürk, E. Çelik, and B. Karlık, “Artificial neural network-based prediction technique for wear loss quantities in Mo coatings," Wear, vol. 261, no. 10, pp. 1064-1068, 2006.

[55] B. Stojanović, A. Vencl, I. Bobić, S. Miladinović, and J. Skerlić, "Experimental optimisation of the tribological behaviour of $\mathrm{Al} / \mathrm{SiC} / \mathrm{Gr}$ hybrid composites based on Taguchi's method and artificial neural network," Journal of the Brazilian Society of Mechanical Sciences and Engineering, vol. 40, no. 6, 2018.

[56] S. B. Mishra, R. Pattnaik, and S. S. Mahapatra, "Parametric analysis of wear behaviour on fused deposition modelling build parts," International Journal of Productivity and Quality Management, vol. 21, no. 3, pp. 375-391, 2017.

[57] V. Kavimani and K. S. Prakash, "Tribological behaviour predictions of r-GO reinforced $\mathrm{Mg}$ composite using ANN coupled Taguchi approach," Journal of Physics and Chemistry of Solids, vol. 110, pp. 409-419, 2017.

[58] T. Kolodziejczyk, R. Toscano, S. Fouvry, and G. E. Morales, "Artificial intelligence as efficient technique for ball bearing fretting wear damage prediction," Wear, vol. 268, no. 1-2, pp. 309-315, 2010.

[59] M. Marani, M. Zeinali, J. Kouam, V. Songmene, and C. K. Mechefske, "Prediction of cutting tool wear during a turning process using artificial intelligence techniques," 
International Journal of Advanced Manufacturing Technology, vol. 111, no. 1-2, pp. 505-515, 2020.

[60] L. Monostori, "AI and machine learning techniques for managing complexity, changes and uncertainties in manufacturing," Engineering Applications of Artificial Intelligence, vol. 16, no. 4, pp. 277-291, 2003.

[61] P. Padmanabhan, A. Arulbrittoraj, R. Srinivasan, and G. Ebenezer, "Study the influence of case hardening and sliding wear parameters on carburised AISI 1211 steel," International Journal of Surface Science and Engineering, vol. 10, no. 5, p. 415, 2016.

[62] D. Y. Pimenov, A. Bustillo, and T. Mikolajczyk, "Artificial intelligence for automatic prediction of required surface roughness by monitoring wear on face mill teeth," Journal of Intelligent Manufacturing, vol. 29, no. 5, pp. 1045-1061, 2017.

[63] C. S. Rao and R. R. Srikant, "Tool wear monitoring-an intelligent approach," Proceedings of the Institution of $\mathrm{Me}$ chanical Engineers - Part B: Journal of Engineering Manufacture, vol. 218, no. 8, pp. 905-912, 2004.

[64] T. Sahraoui, S. Guessasma, N. E. Fenineche, G. Montavon, and C. Coddet, "Friction and wear behaviour prediction of HVOF coatings and electroplated hard chromium using neural computation," Materials Letters, vol. 58, no. 5, pp. 654-660, 2004.

[65] R. G. Silva, S. J. Wilcox, and R. L. Reuben, "Development of a system for monitoring tool wear using artificial intelligence techniques," Proceedings of the Institution of Mechanical Engineers - Part B: Journal of Engineering Manufacture, vol. 220, no. 8, pp. 1333-1346, 2006.

[66] A. Nagaraj and S. Gopalakrishnan, "Modelling wear behavior of aluminium-silicon alloys using generalized feed forward neural network," Tierärztliche Praxis, vol. 40, 2020.

[67] D. Vijay and T. K. Kandavel, "Application of artificial neural network on wear properties of sinter-forged Fe-C-Mo low alloy steel," International Journal of Advanced Intelligence Paradigms, vol. 7, no. 3/4, 2015.

[68] S. Wang, S. Khatir, and M. Abdel Wahab, "Proper Orthogonal Decomposition for the prediction of fretting wear characteristics," Tribology International, vol. 152, Article ID 106545, 2020.

[69] D. Aleksendrić and Č. Duboka, "Fade performance prediction of automotive friction materials by means of artificial neural networks," Wear, vol. 262, no. 7-8, pp. 778-790, 2007.

[70] A. A. Sosimi, O. P. Gbenebor, O. Oyerinde, O. O. Bakare, S. O. Adeosun, and S. A. Olaleye, "Analysing wear behaviour of Al-CaCO3 composites using ANN and Sugeno-type fuzzy inference systems," Neural Computing \& Applications, 2020.

[71] F. Alambeigi, S. M. Khadem, H. Khorsand, and E. S. H. Mirza, "A comparison of performance of artificial intelligence methods in prediction of dry sliding wear behavior," International Journal of Advanced Manufacturing Technology, vol. 84, no. 9-12, pp. 1981-1994, 2015.

[72] A. ArriandiagaLaresgoiti, E. P. Portillo, J. A. G. Sánchez, I. A. Cabanes, and I. R. Pombo, "Virtual sensors for on-line wheel wear and part roughness measurement in the grinding process," Sensors, vol. 14, no. 5, 2014.

[73] A. Bustillo, D. Y. Pimenov, M. Matuszewski, and T. Mikolajczyk, "Using artificial intelligence models for the prediction of surface wear based on surface isotropy levels," Robotics and Computer-Integrated Manufacturing, vol. 53, pp. 215-227, 2018.

[74] R. E. Haber and A. Alique, "Intelligent process supervision for predicting tool wear in machining processes," Mechatronics, vol. 13, no. 8-9, pp. 825-849, 2003.
[75] F. Aydin, "The investigation of the effect of particle size on wear performance of aa7075/al2o3 composites using statistical analysis and different machine learning methods," Advanced Powder Technology, vol. 32, no. 2, 2021.

[76] G. O. Barrionuevo, J. A. Ramos-Grez, M. Walczak, and A. B. Carlos, "Comparative evaluation of supervised machine learning algorithms in the prediction of the relative density of 316L stainless steel fabricated by selective laser melting," International Journal of Advanced Manufacturing Technology, vol. 113, no. 8, 2021.

[77] M. Agarwal, M. Kumar Singh, R. Srivastava, and R. K. Gautam, "Microstructural measurement and artificial neural network analysis for adhesion of tribolayer during sliding wear of powder-chip reinforcement based composites," Measurement, vol. 168, Article ID 108417, 2021.

[78] M. Szala, M. Awtoniuk, L. Łatka, W. Macek, and R. Branco, "Artificial neural network model of hardness, porosity and cavitation erosion wear of APS deposited Al2O3-13 wt\% $\mathrm{TiO} 2$ coatings," Journal of Physics: conference Series, vol. 1736, no. 1, Article ID 012033, 2021.

[79] L. Tyagi, R. Butola, L. Kem, and M. S. Ranganath, "Comparative analysis of response surface methodology and artificial neural network on the wear properties of surface composite fabricated by friction stir processing," Journal of Bio- and Tribo-Corrosion, vol. 7, 2021.

[80] S. Basavarajappa, G. Chandramohan, and J. P. Davim, "Application of Taguchi techniques to study dry sliding wear behavior of metal matrix composites," Materials \& Design, vol. 28, no. 4, pp. 1393-1398, 2007.

[81] Y. Sahin, "Optimization of testing parameters on the wear behavior of metal matrix composites based on the Taguchi method," Materials Science and Engineering: A, vol. 408, no. 1-2, pp. 1-8, 2005.

[82] V. E. Buchanan, P. H. Shipway, and D. G. McCartney, "Microstructure and abrasive wear behavior of shielded metal arc welding hardfacings used in the sugarcane industry," Wear, vol. 263, no. 1-6, pp. 99-110, 2007.

[83] C. S. Ramesh and A. Ahamed, "Friction and wear behavior of cast $\mathrm{Al} 6063$ based in situ metal matrix composites," Wear, vol. 271, no. 9-10, pp. 1928-1939, 2011.

[84] H. Ahlatci, T. Koçer, E. Candan, and H. Çimenoğlu, "Wear behavior of $\mathrm{Al} /(\mathrm{Al} 2 \mathrm{O} 3 \mathrm{p}+\mathrm{SiCp})$ hybrid composites," Tribology International, vol. 39, no. 3, pp. 213-220, 2006.

[85] Y. Sahin and K. Özdin, "A model for the abrasive wear behavior of aluminium based composites," Materials \& Design, vol. 29, no. 3, pp. 728-733, 2008.

[86] S. Basavarajappa, G. Chandramohan, A. Mahadevan, M. Thangavelu, R. Subramanian, and P. Gopalakrishnan, "Influence of sliding speed on the dry sliding wear behavior and the subsurface deformation on hybrid metal matrix composite," Wear, vol. 262, no. 7-8, pp. 1007-1012, 2007.

[87] K. Umanath, K. Palanikumar, and S. T. Selvamani, "Analysis of dry sliding wear behavior of Al6061/SiC/Al2O3 hybrid metal matrix composites," Composites Part B: Engineering, vol. 53, pp. 159-168, 2013.

[88] J. M. Durand, M. Vardavoulias, and M. Jeandin, "Role of reinforcing ceramic particles in the wear behavior of polymerbased model composites," Wear, vol. 181-183, pp. 833-839, 1995.

[89] J. Kondratiuk and P. Kuhn, "Tribological investigation on friction and wear behavior of coatings for hot sheet metal forming," Wear, vol. 270, no. 11-12, pp. 839-849, 2011.

[90] T. Sathish and S. Karthick, "Wear behavior analysis on aluminium alloy 7050 with reinforced $\mathrm{SiC}$ through taguchi 
approach," Journal of Materials Research and Technology, vol. 9, no. 3, 2020.

[91] P. Sharma, K. Paliwal, R. K. Garg, S. Sharma, and D. Khanduja, "A study on wear behavior of Al/6101/graphite composites," Journal of Asian Ceramic Societies, vol. 5, no. 1, pp. 42-48, 2017.

[92] S. A. Alidokht, A. Abdollah-zadeh, and H. Assadi, "Effect of applied load on the dry sliding wear behavior and the subsurface deformation on hybrid metal matrix composite," Wear, vol. 305, no. 1-2, pp. 291-298, 2013.

[93] M. Vrabel, I. Mankova, J. Beno, and J. Tuharský, "Surface roughness prediction using artificial neural networks when drilling udimet 720," Procedia Engineering, vol. 48, pp. 693-700, 2012.

[94] A. Leyland and A. Matthews, "On the significance of the H/E ratio in wear control: a nanocomposite coating approach to optimised tribological behavior," Wear, vol. 246, no. 1-2, pp. 1-11, 2000.

[95] F. Aydin and R. Durgut, "Estimation of wear performance of AZ91 alloy under dry sliding conditions using machine learning methods," Transactions of Nonferrous Metals Society of China, vol. 31, no. 1, pp. 125-137, 2021.

[96] P. Ramkumar, Trends in Mechanical and Biomedical Design, E. T. Akinlabi, P. Ramkumar, and M. Selvaraj, Eds., Springer, Singapore, 2021.

[97] L. Provezza, I. Bodini, C. Petrogalli, M. Lancini, L. Solazzi, and M. Faccoli, "Monitoring the damage evolution in rolling contact fatigue tests using machine learning and vibrations," Metals, vol. 11, 2021.

[98] S. K. Pattnaik, A. Nayak, A. Parida, and S. S. Kumar, "The study of surface roughness and tool wear analysis in turning of aluminum using different advanced cutting tools (january 16, 2021)," in Proceedings of the International Conference on Artificial Intelligence in Manufacturing \& Renewable Energy (ICAIMRE), Bhubaneswar, India, October 2019.

[99] C. S. Lee, Y. H. Kim, K. S. Han, and T. Lim, "Wear behavior of aluminium matrix composite materials," Journal of $M a$ terials Science, vol. 27, no. 3, pp. 793-800, 1992.

[100] B. Gülenç and N. Kahraman, "Wear behavior of bulldozer rollers welded using a submerged arc welding process," Materials and Design, vol. 24, no. 7, pp. 537-542, 2003.

[101] M. Semlitsch and H. G. Willert, "Clinical wear behavior of ultra-high molecular weight polyethylene cups paired with metal and ceramic ball heads in comparison to metal-onmetal pairings of hip joint replacements," Proceedings of the Institution of Mechanical Engineers - Part H: Journal of Engineering in Medicine, vol. 211, no. 1, pp. 73-88, 1997.

[102] K. Sivaprasad, S. K. Babu, S. Natarajan, R. Narayanasamy, B. A. Kumar, and G. Dinesh, "Study on abrasive and erosive wear behavior of $\mathrm{Al}$ 6063/TiB2 in situ composites," Materials Science and Engineering: A, vol. 498, no. 1-2, pp. 495-500, 2008.

[103] L. Natrayan and M. K. Senthil, "Optimization of wear behavior on AA6061/Al2O3/SiC metal matrix composite using squeeze casting technique - statistical analysis," Materials Today Proceedings, vol. 27, 2019.

[104] J. U. Prakash, T. V. Moorthy, and S. Ananth, "Fabrication and sliding wear behavior of metal matrix composites," Applied Mechanics and Materials, vol. 612, pp. 157-162, 2014.

[105] C. S. Ramesh, C. K. Srinivas, and B. H. Channabasappa, "Abrasive wear behavior of laser sintered iron-SiC composites," Wear, vol. 267, no. 11, pp. 1777-1783, 2009.

[106] A. Raj, S. R. Kishore, L. Jose et al., "A survey of electromagnetic metal casting computation designs, present approaches, future possibilities, and practical issues," Eur. Phys. J. Plus, vol. 136, 2021.

[107] G. Hermann, "Artificial intelligence in monitoring and the mechanics of machining," Computers in Industry, vol. 14, no. 1-3, pp. 131-135, 1990.

[108] S. K. Selvaraj, K. Srinivasan, U. Chadha et al., "ContemporaryProgresses in ultrasonic weldingof aluminum metal MatrixComposites," Frontiers in Materials, vol. 8, Article ID 647112, 2021.

[109] A. Sharma, A. Chouhan, L. Pavithran, U. Chadha, and S. K. Selvaraj, "Implementation of LSS framework in automotive component manufacturing: a review, current scenario and future directions," Materials Today Proceedings, vol. 46, 2021.

[110] R. Sivasubramani, A. Verma, G. Rithvik, U. Chadha, and K. S. Senthil, "Influence on nonhomogeneous microstructure formation and its role on tensile and fatigue performance of duplex stainless steel by a solid-state welding process," Materials Today Proceedings, vol. 46, no. 5, 2021.

[111] K. Virmani, C. Deepak, S. Sharma et al., "Nanomaterials for automotive outer panel components: a review," Eur. Phys. J. Plus, vol. 136, 2021.

[112] K. S. Senthil, R. Ramesh, M. Tharun et al., "New developments in carbon-based nanomaterials for automotive brake pad applications and future challenges," Journal of Nanomaterials, vol. 2021, Article ID 6787435, 24 pages, 2021.

[113] M. Dharnidharka, U. Chadha, L. M. Dasari et al., "Optical tomography in additive manufacturing: a review, processes, open problems, and new opportunities," Eur. Phys. J. Plus, vol. 136, 2021.

[114] T. Ghimire, A. Joshi, S. Sen, K. Chinmay, U. Chadha, and K. S. Senthil, "Blockchain in additive manufacturing processes: recent trends \& its future possibilities," Materials Today Proceedings, in Press, 2021.

[115] S. D. Mamdiwar and Z. Shakruwala, "Recent advances on IoT-assisted wearable sensor systems for healthcare monitoring," Biosensors, vol. 11, no. 11, p. 372, 2021.

[116] T.. Pati, P. H. Kabra, and U. Chadha, "Statistical quality study of the parts produced in an automobile industry: a Daimler India case study," In IOP Conference Series: Materials Science and Engineering, vol. 1206, no. 1, Article ID 012022, 2021.

[117] H. Unal and A. Mimaroglu, "Friction and wear behaviour of unfilled engineering thermoplastics," Materials \& Design, vol. 24, no. 3, pp. 183-187, 2003. 